\title{
Daratumumab Monotherapy in Heavily Pretreated Asian Patients With Relapsed and Refractory Multiple Myeloma: A Real-world Experience
}

\author{
JA MIN BYUN ${ }^{1}$, SUNG-SOO YOON ${ }^{1}$, YOUNGIL KOH ${ }^{1}$, INHO KIM ${ }^{1}$, \\ JAEMIN JO ${ }^{2}$, HYUNKYUNG PARK ${ }^{3}$, JEONG-OK LEE ${ }^{4}$ and JIYUN LEE ${ }^{4}$ \\ ${ }^{1}$ Department of Internal Medicine, Seoul National University College of Medicine, \\ Seoul National University Hospital, Seoul, Republic of Korea; \\ ${ }^{2}$ Department of Internal Medicine, Jeju National University Hospital, Jeju, Republic of Korea; \\ ${ }^{3}$ Department of Internal Medicine, Seoul National University Boramae Medical Center, Seoul, Republic of Korea; \\ ${ }^{4}$ Department of Internal Medicine, Seoul National University Bundang Hospital, Seongnam, Republic of Korea
}

\begin{abstract}
Background/Aim: Daratumumab is a promising novel agent for relapsed/refractory multiple myeloma (RRMM). However, there are limited data on its efficacy and toxicity profiles in real-world patients, especially in the Asian population. Patients and Methods: This was a multicenter, retrospective, longitudinal cohort study set between January 2017 and April 2019. We collected and analyzed clinical and survival data of 21 patients treated with daratumumab monotherapy. All patients were previously exposed to proteasome inhibitors and immunomodulatory drugs. Results: The overall response rate was $42.1 \%$, including one complete remission (4.8\%) and three very good partial responses (14.3\%). The cycles of daratumumab delivered were three (range $=1-10$ cycles) and the median progression-free survival was 6 months, while the overall survival was not reached. Infusion reaction was observed in nine patients (42.9\%), and one discontinued permanently. Fatigue was the most common adverse event (52.4\%), and there were five cases of documented infection during daratumumab treatment, two of them leading to the death of the patient. Conclusion: Daratumumab monotherapy showed fairly promising activity with modest tolerance in heavily treated Asian RRMM patients.
\end{abstract}

Multiple myeloma (MM) marks the third most common hematological malignancy in Korea (1), and although the

Correspondence to: Sung-Soo Yoon, MD, Ph.D., Department of Internal Medicine, Seoul National University Hospital, 101, Daehak-ro, Jongro-gu, Seoul 03080, Republic of Korea. Tel: +82 220723079, Fax: +82 27629662, e-mail: ssysmc@snu.ac.kr

Key Words: Daratumumab, multiple myeloma, relapsed, real-world, Asian. survival outcomes have improved significantly with new proteasome inhibitors (PI) and immunomodulatory drugs (IMiD) (2-4), most patients still die from refractory disease (5). More specifically, for patients with relapsed and refractory MM (RRMM) who are refractory to both PI and $\mathrm{IMiD}$, the expected median overall survival (OS) is eight months (6). Considering the fact that treatment of these patients is usually complicated by cytopenias and comorbidities, alternative agents that target novel pathways with favorable tolerability are required.

Daratumumab is a first-in-class human immunoglobulin kappa monoclonal antibody targeting CD38 (7). Clinical trials with daratumumab monotherapy in RRMM have shown substantial efficacy and favorable safety profiles (810), leading to its approval by the U.S. Food and Drug Administration (FDA) in 2015 and by the Korean FDA in 2017. However, these trials excluded patients with poor performance status and other significant co-morbidities, thus their results cannot be immediately implemented into realworld practice. Real-world data concerning daratumumab monotherapy, especially from the Asian population, are still lacking. Importantly, since it has been known that Asian patients tend to be less tolerable to chemotherapy (11) often leading to dose modifications, the toxicity profile is of special interest. To this end, we carried out this study.

\section{Patients and Methods}

Study design and subjects. This was a multicenter, retrospective, longitudinal cohort study of MM patients over 18 years old. The study period was set between January 2017 and April 2019. Initially, 55 patients were identified as being subjected to daratumumab treatment, but 27 were excluded as they were participants of clinical trials. After excluding an additional two patients for a previous history of daratumumab-based trial, three for combination therapy, 
Table I. Baseline characteristics at daratumumab treatment.

\begin{tabular}{|c|c|c|}
\hline$\%$ & & $\mathrm{~N}, \%$ \\
\hline \multirow[t]{4}{*}{ Age (years) } & Median (range) & $69(55-86)$ \\
\hline & 18 to $<65$ & $7(33.3)$ \\
\hline & 65 to $<75$ & $9(42.9)$ \\
\hline & $\geq 75$ & $5(23.8$ \\
\hline Gender & Male & $10(47.6)$ \\
\hline \multirow[t]{2}{*}{ Performance status } & ECOG $0-1$ & $4(19.0)$ \\
\hline & $\mathrm{ECOG} \geq 2$ & $17(81.0)$ \\
\hline ISS & I/I/III & $\begin{array}{c}7(33.3) / 5(23.8) \\
9(42.9)\end{array}$ \\
\hline \multirow[t]{6}{*}{ Cytogenetics profile } & $\mathrm{t}(4 ; 14)$ & $1 / 13(7.7)$ \\
\hline & del17p & $2 / 13(15.4)$ \\
\hline & $\mathrm{t}(14 ; 16)$ & $0 / 13$ \\
\hline & del13q & $8 / 13(61.5)$ \\
\hline & $\operatorname{amp} 1 \mathrm{q} 21$ & $5 / 13(38.5)$ \\
\hline & Missing & 8 \\
\hline \multicolumn{2}{|l|}{ Extramedullary involvement } & $8(38.1)$ \\
\hline \multicolumn{2}{|l|}{ Bone involvement } & $17(81.0)$ \\
\hline \multirow[t]{2}{*}{ Lines of previous therapy } & Median (range) & $4(3-8)$ \\
\hline & $>3$ & $17(81.0)$ \\
\hline \multirow[t]{3}{*}{ Previous proteasome inhibitor } & Bortezomib & $21(100.0)$ \\
\hline & Ixazomib & $1(4.8)$ \\
\hline & Carfilzomib & $14(66.7)$ \\
\hline \multirow[t]{3}{*}{ Previous IMiD } & Thalidomide & $11(52.4)$ \\
\hline & Lenalidomide & $21(100.0)$ \\
\hline & Pomalidomide & $20(95.2)$ \\
\hline \multirow[t]{7}{*}{ Refractory to } & Last line of therapy & $19(90.5)$ \\
\hline & Double refractory & $16(76.2)$ \\
\hline & Bortezomib & $9 / 21(42.9)$ \\
\hline & Carfilzomib & $14 / 14(100.0)$ \\
\hline & Thalidomide & $5 / 11(45.5)$ \\
\hline & Lenalidomide & 20/21 (95.2) \\
\hline & Pomalidomide & $18 / 20(90.0)$ \\
\hline \multirow[t]{2}{*}{ Previous HSCT } & autoSCT & $8(38.1)$ \\
\hline & alloSCT & $2(9.5)$ \\
\hline \multirow{4}{*}{$\begin{array}{l}\text { Lab findings at daratumumab start } \\
\text { mean ( } \pm \text { standard deviation) }\end{array}$} & WBC $\left(10^{3} / 1\right)$ & $4554(1963)$ \\
\hline & $\mathrm{Hb}(\mathrm{g} / \mathrm{dl})$ & $10.2(2.1)$ \\
\hline & Plt $\left(10^{9} / 1\right)$ & $148(78)$ \\
\hline & $\mathrm{Cr}$ & $1.3(1.0)$ \\
\hline \multirow{3}{*}{$\begin{array}{l}\text { Renal function } \\
\text { (creatinine clearance) }\end{array}$} & $\geq 60 \mathrm{ml} / \mathrm{min}$ & $11(52.4)$ \\
\hline & 30 to $<60 \mathrm{ml} / \mathrm{min}$ & $7(33.3)$ \\
\hline & $<30 \mathrm{ml} / \mathrm{min}$ & $3(14.3)$ \\
\hline
\end{tabular}

ECOG: Eastern Cooperative Oncology Group performance status; ISS: International Staging System; IMiD: immunomodulatory drugs; HSCT: hematopoietic stem cell transplantation; autoSCT: autologous stem cell transplantation; alloSCT: allogeneic stem cell transplantation.

and two patients for insufficient data, a total of 21 patients were enrolled. Their medical records were reviewed and analyzed for demographics, disease characteristics, response to daratumumab, adverse events, and survival outcomes. This study was conducted according to the Declaration of Helsinki and was approved by the institutional review board of all the participating hospitals (H-1906035-1038).

Daratumumab treatment. Daratumumab was administered as a single drug at the dose of $16 \mathrm{mg} / \mathrm{kg}$ once weekly for the first 8
Table II. Overall best response.

\begin{tabular}{lc}
\hline Median number of cycles & $3(1-10)$ \\
Best response to daratumumab & \\
CR & $1(4.8 \%)$ \\
VGPR & $3(14.3 \%)$ \\
PR & $4(19.0 \%)$ \\
MR & $3(14 / 3 \%)$ \\
SD & $4(19.0 \%)$ \\
PD & $4(19.0 \%)$ \\
NE* & $2(9.5 \%)$ \\
Overall response rate** & $8 / 19(42.1 \%)$ \\
Clinical benefit rate** & $11 / 19(57.9 \%)$ \\
\hline
\end{tabular}

CR: Complete response; VGPR: very good partial response; PR: partial response; MR: minimal response; SD: stable disease; PD: progressive disease; NE: not evaluable. *Response not evaluable due to death by sepsis during the first cycle of daratumumab. **For patients with evaluable responses only.

weeks (cycles 1 and 2), then every 2 weeks for 16 weeks (cycles 3 to 6), and then once every 4 weeks thereafter (cycles 7 and higher) until disease progression or unacceptable toxicity. For infusionrelated reaction (IRR) prevention, the patients received premedication comprising methylprednisolone or an equivalent, acetaminophen, and diphenhydramine or an equivalent one hour prior to administration of daratumumab.

Definitions and statistical analysis. The response to daratumumab was evaluated according to the International Myeloma Working Group response criteria (12). The overall response rate (ORR) was defined as the proportion of patients achieving at least a partial response (PR). The clinical benefit rate was defined as the proportion of patients achieving at least a minimal response (MR). The adverse events (AE) were assessed according to the National Cancer Institute Common Terminology Criteria for Adverse Events (version 4.03). Refractory status was defined as disease progression on or within 60 days of the last treatment. The OS and progressionfree survival (PFS) curves were estimated using the Kaplan-Meier method. OS was defined as the time from daratumumab start date to death from any cause. PFS was defined as the duration from daratumumab start date to disease progression or death. If patients survived without death or progression, survival was censored at the latest date of follow-up when no death or progression was confirmed, and data available up to June 2019 were used. All data were analyzed using the Statistical Package for the Social Sciences software (IBM ${ }^{\circledR}$ SPSS $^{\circledR}$ Statistics, version 22.0). $p$-Values of $<0.05$ were considered statistically significant.

\section{Results}

Patient characteristics. The characteristics of the enrolled patients are listed in Table I. The median time from MM diagnosis to daratumumab monotherapy was 54 months (range $=12-119$ months). The median of previous lines of therapy was 4 (range $=3-8$ ), all the patients were previously exposed to at least one PI and IMiD, and the majority (76.2\%) of the patients were double-refractory. Nineteen $(90.5 \%)$ 


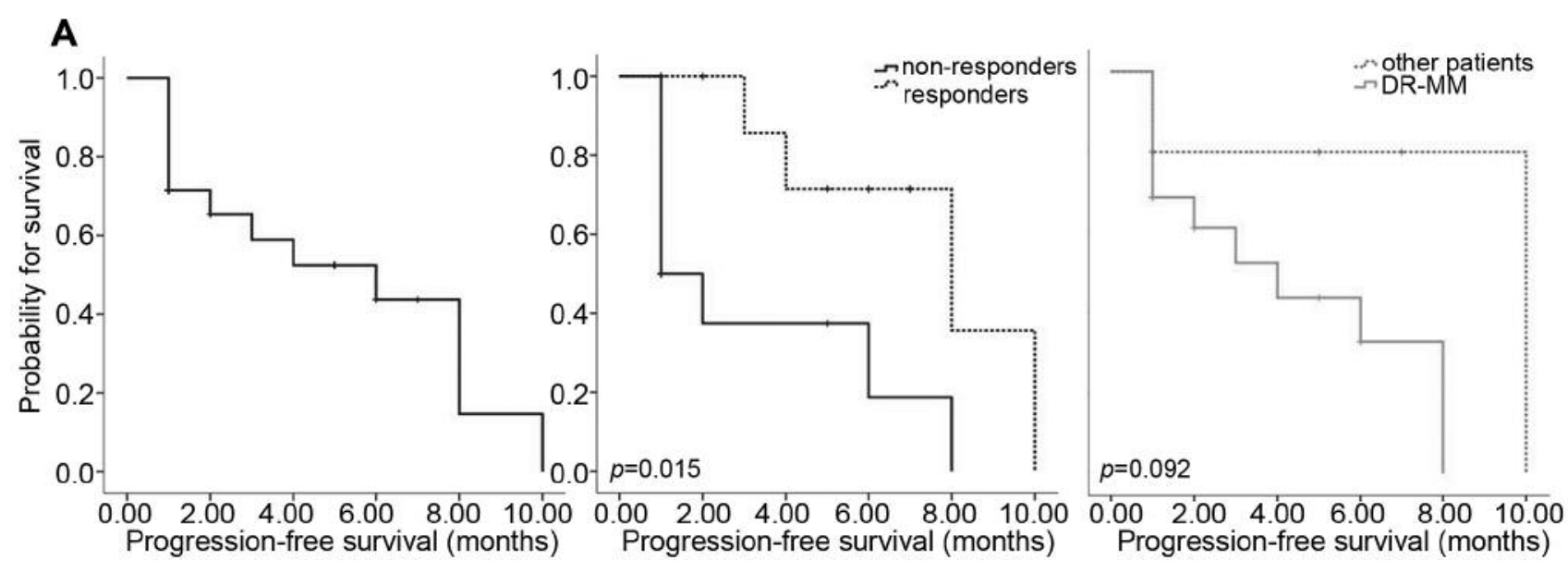

B

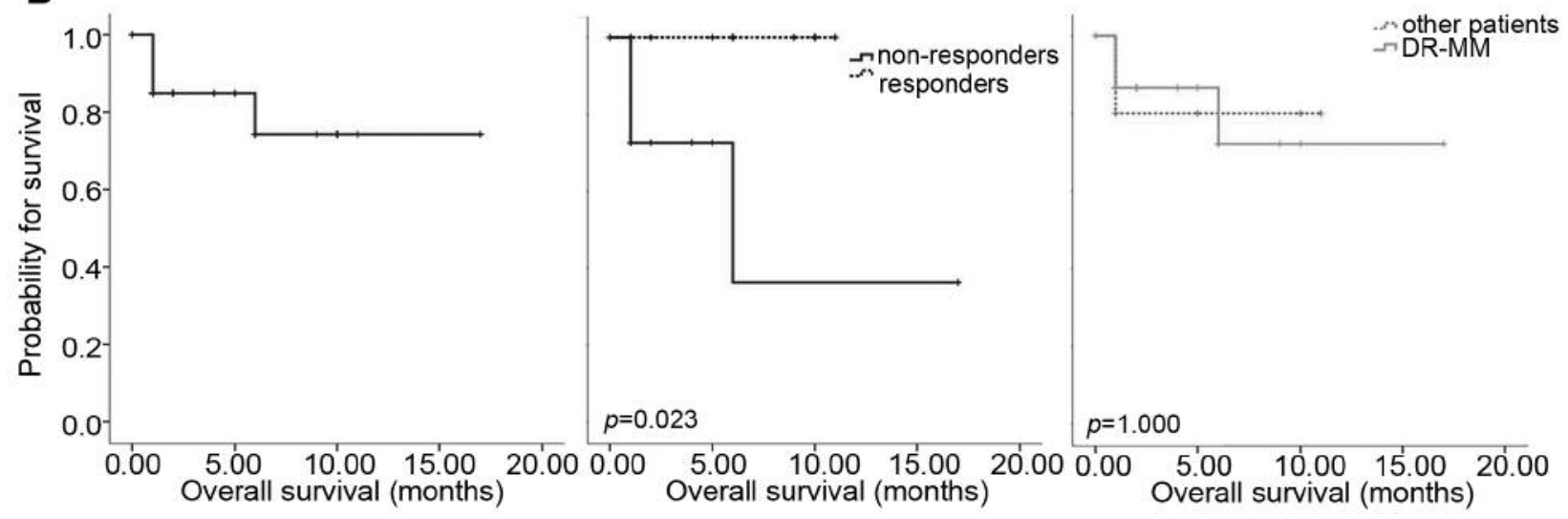

Figure 1. Survival curves. A) PFS of all patients (left), according to daratumumab response (middle), and according to double-refractoriness (right). B) OS of all patients (left), according to daratumumab response (middle), and according to double-refractoriness (right). PFS: Progression-free survival; OS: overall survival; DR-MM: double-refractory multiple myeloma.

patients were refractory to the last line of therapy. At the start of daratumumab monotherapy, there were three patients with creatinine clearance $<30 \mathrm{ml} / \mathrm{min}$. Extramedullary involvement was seen in eight $(38.1 \%)$ patients. Most patients had an ECOG performance score of 2 or higher, and there was one patient with ECOG 3. Cytogenetic risk by fluorescence in situ hybridization (FISH) was available in 13 patients, and among them, two were identified as high risk [i.e. $\mathrm{t}(4 ; 14), \mathrm{t}(14 ; 16)$ and $17 \mathrm{p}$ deletion].

Daratumumab efficacy. The enrolled patients received a median of 3 cycles (range $=1-10$ cycles) of daratumumab (Table II). Among the 19 patients with evaluable response, the ORR was $42.1 \%(8 / 19)$, including one complete response (CR) and three very good partial responses (VGPR). The clinical benefit was seen in $57.9 \%$ of the patients (11/19), and the median time to response for these patients was two months (range=1-6 months). The three patients with compromised renal function did not benefit from daratumumab treatment. As shown in Figure 1, the median PFS was six months (95\%CI=1.1-10.9 months) and the median OS was not reached. The median PFS for responders $(\mathrm{CR}+\mathrm{VGPR}+\mathrm{PR})$ was eight months while for nonresponders $[\mathrm{MR}+$ stable disease $(\mathrm{SD})+$ progressive disease (PD)] the median PFS was one month $(p=0.015)$. The median OS for responders was not reached, while for nonresponders the median OS was six months $(p=0.023)$. The patients with double-refractory MM (DR-MM) to both PI and IMiD were associated with a trend towards worse PFS (median PFS for DR-MM patients 4 months $v s .10$ months for others, $p=0.092$ ) but the difference did not show a statistical significance. The OS was similar between the two groups $(p=1.000)$. Due to the limited number of patients with available cytogenetic profiles and even smaller number of patients with high risk abnormalities (2 patients classified as high risk: 1 with both $\mathrm{t}(4 ; 14)$ and del17p, and 1 with 
Table III. Adverse events.

\begin{tabular}{lcc}
\hline & Any grade & Grade 3 or higher \\
\hline Infusion-related reaction & $9(42.9 \%)$ & $4(19.0 \%)$ \\
$\quad$ Dyspnea & 7 & 3 \\
$\quad$ Nausea & 1 & 1 \\
Cough & 2 & 0 \\
Anemia & $5(23.8 \%)$ & $4(19.0 \%)$ \\
Thrombocytopenia & $8(38.1 \%)$ & $6(28.6 \%)$ \\
Neutropenia & $6(28.6 \%)$ & $5(23.8 \%)$ \\
$\quad$ Febrile neutropenia & 5 & 5 \\
Elevation of liver enzyme & 0 & 0 \\
Fatigue & $11(52.4 \%)$ & $2(9.5 \%)$ \\
Infection & $6(28.6 \%)$ & $5(23.8 \%)$ \\
$\quad$ Bacteremia & 3 & 3 \\
Pneumonia & 2 & 2 \\
Other infection & 1 & 0 \\
\hline
\end{tabular}

del17p), the impact of risk stratification on PFS and OS could not be well established.

Daratumumab safety. IRR occurred in $42.9 \%(9 / 18)$ of the patients. There were four cases with grade 3 or higher IRR in the form of severe nausea and vomiting combined with a generalized rash leading to permanent daratumumab discontinuation in one patient, and dyspnea (bronchospasm) requiring immediate intervention in three patients. The latter three patients continued subsequent daratumumab treatment on desensitization protocol.

There were six cases of documented infection: one with Pseudomonas bacteremia after cycle 3, one with gramnegative rod bacteremia during cycle 1 leading to patient's demise, one with Corynebacterium bacteremia during cycle 1 to patient's demise, one with atypical pneumonia after cycle 5, one with Pneumocystis pneumonia after cycle 3, and one with Herpes gingivostomatitis after cycle 1 . The details of other AEs are described in Table III. The most common $\mathrm{AE}$ was fatigue, which was reported in $52.4 \%$ (11/21) of the patients. No new safety issue was raised.

Subsequent treatment after daratumumab. At the time of data cut-off, four patients had expired and eight were still on daratumumab monotherapy. There were two patients who expired due to bacteremia during the first cycles of daratumumab, one due to progressive disease while on daratumumab and one due to recurrent esophageal cancercausing airway obstruction. For the remaining nine patients, subsequent treatment schema is shown in Table IV. All but one proceeded to the next line therapy, and the most often used regimen was bendamustine with prednisone. For the one patient who did not receive any subsequent treatment, best supportive care was offered due to the patient's refusal for further treatment.
Table IV. Subsequent treatment after daratumumab.

\begin{tabular}{lcccc}
\hline Patient & $\begin{array}{c}\text { Subsequent } \\
\text { treatment }\end{array}$ & $\begin{array}{c}\text { Current } \\
\text { status }\end{array}$ & $\begin{array}{c}\text { Survival* } \\
\text { (months) }\end{array}$ & $\begin{array}{c}\text { Overall } \\
\text { survival** } \\
\text { (months) }\end{array}$ \\
\hline 1 & Benda/Pd $\rightarrow$ PCD & Alive & 9 & 74 \\
2 & VAD $\rightarrow$ MPT $\rightarrow$ Benda/Pd & Alive & 3 & 22 \\
3 & PCD & Alive & 1 & 46 \\
4 & Supportive care only & Alive & 1 & 49 \\
5 & DCEP & Alive & 1 & 119 \\
6 & Benda/Pd & Alive & 1 & 95 \\
7 & VelDex & Alive & 3 & 41 \\
8 & MP & Alive & 6 & 78 \\
9 & DCEP & Alive & 1 & 57 \\
\hline
\end{tabular}

Benda/Pd: Bendamustine and prednisone; PCD: pomalidomide, cyclophosphamide, dexamethasone; VAD: vincristine, doxorubicin, dexamethasone; MPT: melphalan, prednisolone, thalidomide; DCEP: dexamethasone, cyclophosphamide, etoposide, cisplatin; VelDex: bortezomib, dexamethasone; MP: melphalan, prednisolone. *Time from the daratumumab progression date to the last follow-up. **Time from multiple myeloma diagnosis to the last follow-up.

\section{Discussion}

As the treatment landscape of MM continues to evolve, we are being introduced to a newer class of anti-myeloma drugs and immunotherapy has emerged as one of the major players in recent years. In this study, we evaluated the efficacy and tolerability of daratumumab, the first monoclonal antibody to demonstrate single agent clinical activity in $\mathrm{MM}$ treatment, in Asian RRMM patients. With a median of four lines of previous treatment and a median time from MM diagnosis to daratumumab treatment of 54 months, the baseline characteristics of our patients were similar to those from the SIRUIS trial (8) and GEN501 trial (9) (Table V). Also, although the cytogenetic profiles were only available in 13 patients, the percentages of high-risk abnormalities were comparable to previous studies. Furthermore, the percentages of patients previously treated with PIs and IMiDs and patients with DR-MM were similar to the abovementioned clinical trials: if anything, with $66.7 \%$ of the patients having been treated with carfilzomib and $95.2 \%$ with pomalidomide, the proportion of patients exposed to next-generation PI and IMiD were higher in our study. Even so, daratumumab monotherapy proved to have a significant clinical activity with ORR of $42.1 \%$ including $19.0 \%$ of VGPR or better in our study. In fact, the response rate seems to be higher than expected in Korean patients (13). One interesting observation was the higher proportion of patients harboring del13q in our cohort (Table I). The number of patients is too small and treatment schema too heterogeneous to grant this observation any clinical implications. However, since this seems to be the only notable difference between 
Table V. Comparison with previous studies involving patients receiving daratumumab $16 \mathrm{mg} / \mathrm{kg}$.

\begin{tabular}{|c|c|c|c|c|c|c|c|c|c|c|c|}
\hline Country & $\mathrm{Pt}$ & $\begin{array}{l}\text { Lines of } \\
\text { previous tx }\end{array}$ & $\begin{array}{l}\text { MM dx } \\
\text { to dara }\end{array}$ & $\begin{array}{c}\text { DR-MM } \\
(\%)\end{array}$ & $\begin{array}{c}\text { ORR } \\
(\mathrm{N}, \%)\end{array}$ & $\begin{array}{c}\text { Clinical benefit } \\
(\mathrm{N}, \%)\end{array}$ & $\begin{array}{l}\text { PFS } \\
(\mathrm{mo})\end{array}$ & $\begin{array}{l}\mathrm{OS} \\
(\mathrm{mo})\end{array}$ & $\begin{array}{c}\mathrm{IRR} \geq \mathrm{Gr} 3 \\
(\mathrm{~N}, \%)\end{array}$ & $\begin{array}{c}\text { Infection } \geq \mathrm{Gr} 3 \\
(\mathrm{~N}, \%)\end{array}$ & Remark \\
\hline Current & 21 & $4(3-8)$ & $54 \mathrm{mo}$ & 76.2 & $8 / 19(42.1)$ & $11 / 19(57.9)$ & 6.0 & NR & $4(19.0)$ & $5(23.8)$ & \\
\hline Korea (13) & 16 & $4(2-8)$ & $83.5 \mathrm{mo}$ & 43.8 & $9 / 16(56.3)$ & $11 / 16(68.8)$ & 2.7 & 10 & $2(12.5)$ & $6(37.5)$ & \\
\hline Poland (14) & 30 & $4(2-10)$ & $4.1 \mathrm{yr}$ & 50.0 & $12 / 28(42.8)$ & NA & 9.5 & 13.8 & $2(6.7)$ & $5(16.7)$ & \\
\hline France (16) & 41 & $4(2-9)$ & NA & 58.5 & $10 / 41(24.4)$ & $16 / 41(39.0)$ & 1.9 & 6.5 & $1(2.4)$ & $4(9.8)$ & \\
\hline SIRIUS (8) & 106 & $5(2-14)$ & $4.8 \mathrm{yr}$ & 95.0 & $31 / 106(29.2)$ & $36 / 106(34.0)$ & 3.7 & 17.5 & $5(5.0)$ & $\begin{array}{l}\text { All Gr } 3 \text { or } \\
4 \text { AE } 23 \%\end{array}$ & $\begin{array}{c}4(4 \%) \text { Asian } \\
\text { patients }\end{array}$ \\
\hline GEN501(9) & 42 & $4(2-12)$ & $68.1 \mathrm{mo}$ & 64.0 & $15 / 42(36.0)$ & $19 / 42(45.2)$ & 5.6 & NA & $\begin{array}{l}\text { All Gr } 3 \text { or } \\
4 \text { AE } 26 \%\end{array}$ & $4(10.0)$ & \\
\hline
\end{tabular}

Tx: Therapy; MM: multiple myeloma; dx: diagnosis; dara: daratumumab; DR-MM: double refractory multiple myeloma; ORR: overall response rate; PFS: progression-free survival; mo: months; OS: overall survival; IRR: infusion-related reaction; Gr: grade; yr: years; NA: not available.

our patients compared to patients enrolled in clinical trials, corroborative research might be necessary.

As for the safety of daratumumab, though no new toxicity signal was identified, there were more grade 3 or higher IRRs and infections in our cohort compared to previous reports based on both clinical trials and real-life experience (Table V). Notably, two patients $(9.5 \%)$ expired during the first cycle of daratumumab due to sepsis. Infection was not necessarily associated with compromised bone marrow function as most patients had stable hemogram at the start of daratumumab (Table I). We do not routinely use prophylactic antibiotics or antifungals with daratumumab in Korea. As evident from another Korean report on real-world experience with daratumumab (13), the high rate of infection complications seems to be a true finding. Further studies from other East Asian countries are needed to optimize the supportive care when using daratumumab. For IRRs, although more patients in our study experienced grade 3 or higher IRRs, they were manageable and all but one continued with daratumumab therapy.

One of the limitations of this study is that we could not establish the response of daratumumab in DR-MM due to the small number of patients. Conflicting results have been reported regarding the role of daratumumab in DR-MM. While Usmani et al. (6) delineated the benefit of daratumumab irrespective of refractory status to PIs and IMiDs, SalomonPerzynski et al. (14) showed that daratumumab cannot overcome the double-refractoriness in a recent report. In our study, DR-MM was associated with shorter PFS to daratumumab but the difference did not reach statistical significance and there was no difference in OS. A larger number of patients is needed to confirm the efficacy of daratumumab in DR-MM treatment. Also, we were not able to determine the predictive marker for daratumumab response. It has been suggested that IgG myeloma responds better to daratumumab than non-IgG myeloma $(15,16)$, but in our cohort only one patient out of the four patients with VGPR or $\mathrm{CR}$ had IgG myeloma. Other limitations include the short follow-up period and the limited availability of cytogenetic profiles to evaluate the impact of risk stratification on the prognosis. However, these limitations do not diminish the importance of our findings that highlight the need for realworld data to complement the results of published clinical trials, especially across the different ethnicities.

In conclusion, daratumumab monotherapy showed a fairly promising activity, but relatively modest tolerance in heavily treated Asian RRMM patients.

\section{Conflicts of Interest}

There are no conflicts of interest to disclose regarding this study.

\section{Authors' Contributions}

Designed the study: Ja Min Byun, Jaemin Jo, Sung-Soo Yoon. Paient enrollment and data collection: Sung-Soo Yoon, Youngil Koh, Inho Kim, Jeong-Ok Lee, Jiyun Lee. Analyzed the data: Ja Min Byun, Hyunkyung Park, Jaemin Jo. Wrote the paper: Ja Min Byun, Sung-Soo Yoon. Revised the paper: all the Authors.

\section{Acknowledgements}

The results of this study have been submitted to the 17th International Myeloma Workshop (IMW) 2019, Boston, MA, USA. This research was supported by a grant of the Korea Health Technology R\&D Project through the Korea Health Industry Development Institute (KHIDI), funded by the Ministry of Health \& Welfare, Republic of Korea (grant number: HI14C2399).

\section{References}

1 Jung KW, Won YJ, Kong HJ and Lee ES: Prediction of Cancer Incidence and Mortality in Korea, 2019. Cancer Res Treat 51: 431-437, 2019. PMID: 30913864. DOI: 10.4143/crt.2019.1392 
2 Dimopoulos M, Spencer A, Attal M, Prince HM, Harousseau JL, Dmoszynska A, San Miguel J, Hellmann A, Facon T, Foà R, Corso A, Masliak Z, Olesnyckyj M, Yu Z, Patin J, Zeldis JB and Knight RD; Multiple Myeloma (010) Study Investigators: Lenalidomide plus dexamethasone for relapsed or refractory multiple myeloma. N Engl J Med 357: 2123-2132, 2007. PMID: 18032762. DOI: $10.1056 /$ NEJMoa070594

3 Mateos MV, Richardson PG, Schlag R, Khuageva NK, Dimopoulos MA, Shpilberg O, Kropff M, Spicka I, Petrucci MT, Palumbo A, Samoilova OS, Dmoszynska A, Abdulkadyrov KM, Schots R, Jiang B, Esseltine DL, Liu K, Cakana A, van de Velde $\mathrm{H}$ and San Miguel JF: Bortezomib plus melphalan and prednisone compared with melphalan and prednisone in previously untreated multiple myeloma: updated follow-up and impact of subsequent therapy in the phase III VISTA trial. J Clin Oncol 28: 2259-2266, 2010. PMID: 20368561. DOI: 10.1200/ JCO.2009.26.0638

4 Stewart AK, Rajkumar SV, Dimopoulos MA, Masszi T, Spicka I, Oriol A, Hajek R, Rosinol L, Siegel DS, Mihaylov GG, Goranova-Marinova V, Rajnics P, Suvorov A, Niesvizky R, Jakubowiak AJ, San-Miguel JF, Ludwig H, Wang M, Maisnar V, Minarik J, Bensinger WI, Mateos MV, Ben-Yehuda D, Kukreti V, Zojwalla N, Tonda ME, Yang X, Xing B, Moreau P and Palumbo A: Carfilzomib, lenalidomide, and dexamethasone for relapsed multiple myeloma. N Engl J Med 372(2): 142-152, 2015. PMID: 25482145. DOI: 10.1056/NEJMoa1411321

5. Turesson I, Velez R, Kristinsson SY and Landgren O: Patterns of improved survival in patients with multiple myeloma in the twenty-first century: A population-based study. J Clin Oncol 28(5): 830-834, 2010. PMID: 20038719. DOI: 10.1200/jco.2009. 25.4177

6 Usmani S, Ahmadi T, Ng Y, Lam A, Desai A, Potluri R and Mehra M: Analysis of real-world data on overall survival in multiple myeloma patients with $\geq 3$ prior lines of therapy including a proteasome inhibitor (pi) and an immunomodulatory drug (imid), or double refractory to a pi and an imid. Oncologist 21(11): 1355-1361, 2016. PMID: 27486203. DOI: $10.1634 /$ theo ncologist.2016-0104

7 de Weers M, Tai YT, van der Veer MS, Bakker JM, Vink T, Jacobs DC, Oomen LA, Peipp M, Valerius T, Slootstra JW, Mutis T, Bleeker WK, Anderson KC, Lokhorst HM, van de Winkel JG and Parren PW: Daratumumab, a novel therapeutic human cd38 monoclonal antibody, induces killing of multiple myeloma and other hematological tumors. J Immunol 186(3): 1840-1848, 2011. PMID: 21187443. DOI: 10.4049/jimmunol.1003032

8 Lonial S, Weiss BM, Usmani SZ, Singhal S, Chari A, Bahlis NJ, Belch A, Krishnan A, Vescio RA, Mateos MV, Mazumder A, Orlowski RZ, Sutherland HJ, Blade J, Scott EC, Oriol A, Berdeja J, Gharibo M, Stevens DA, LeBlanc R, Sebag M, Callander N, Jakubowiak A, White D, de la Rubia J, Richardson PG, Lisby S, Feng H, Uhlar CM, Khan I, Ahmadi T and Voorhees PM: Daratumumab monotherapy in patients with treatment-refractory multiple myeloma (sirius): An open-label, randomised, phase 2 trial. Lancet 387(10027): 1551-1560, 2016. PMID: 26778538. DOI: 10.1016/s0140-6736(15)01120-4

9 Lokhorst HM, Plesner T, Laubach JP, Nahi H, Gimsing P, Hansson M, Minnema MC, Lassen U, Krejcik J, Palumbo A, van de Donk NW, Ahmadi T, Khan I, Uhlar CM, Wang J, Sasser AK, Losic N, Lisby S, Basse L, Brun N and Richardson PG: Targeting cd38 with daratumumab monotherapy in multiple myeloma. $\mathrm{N}$ Engl J Med 373(13): 1207-1219, 2015. PMID: 26308596. DOI: 10.1056/NEJMoa1506348

10 Usmani SZ, Diels J, Ito T, Mehra M, Khan I and Lam A: Daratumumab monotherapy compared with historical control data in heavily pretreated and highly refractory patients with multiple myeloma: An adjusted treatment comparison. Am J Hematol 92(8): E146-E152, 2017. PMID: 28474745. DOI: 10.1002/ajh.24781

11 O'Donnell PH and Dolan ME: Cancer pharmacoethnicity: Ethnic differences in susceptibility to the effects of chemotherapy. Clin Cancer Res 15(15): 4806-4814, 2009. PMID: 19622575. DOI: 10.1158/1078-0432.ccr-09-0344

12 Rajkumar SV, Harousseau JL, Durie B, Anderson KC, Dimopoulos M, Kyle R, Blade J, Richardson P, Orlowski R, Siegel D, Jagannath S, Facon T, Avet-Loiseau H, Lonial S, Palumbo A, Zonder J, Ludwig H, Vesole D, Sezer O, Munshi $\mathrm{NC}$ and San Miguel J: Consensus recommendations for the uniform reporting of clinical trials: Report of the international myeloma workshop consensus panel 1. Blood 117(18): 46914695, 2011. PMID: 21292775. DOI: 10.1182/blood-2010-10299487

13 Park SS, Eom HS, Kim JS, Koh Y, Choi CW, Lee JJ, Kim K, Suh C, Lee JH and Min CK: Brief report: Clinical experiences after emergency use of daratumumab monotherapy for relapsed or refractory multiple myeloma in real practice. Jpn J Clin Oncol 49(1): 92-95, 2019. PMID: 30476124. DOI: 10.1093/jjco/hyy 177

14 Salomon-Perzynski A, Walter-Croneck A, Usnarska-Zubkiewicz L, Dytfeld D, Zielinska P, Wojciechowska M, Holojda J, Robak P, Pasternak A, Knopinska-Posluszny W, Hawrylecka D, Wojtowicz M, Szeremet A, Osowiecki M, Mordak-Domagala M, Zaucha JM, Giannopoulos K, Warzocha K and Jamroziak K: Efficacy of daratumumab monotherapy in real-world heavily pretreated patients with relapsed or refractory multiple myeloma. Adv Med Sci 64(2): 349-355, 2019. PMID: 31125864. DOI: 10.1016/j.advms.2019.05.001

15 Yan X, Clemens PL, Puchalski T, Lonial S, Lokhorst H, Voorhees PM, Usmani S, Richardson PG, Plesner T, Liu K, Orlowski RZ, Losic N, Jansson R, Ahmadi T, Lantz K, Ruixo JJP, Zhou $\mathrm{H}$ and $\mathrm{Xu}$ XS: Influence of disease and patient characteristics on daratumumab exposure and clinical outcomes in relapsed or refractory multiple myeloma. Clin Pharmacokinet 57(4): 529-538, 2018. PMID: 28983805. DOI: $10.1007 / \mathrm{s} 40262-$ 017-0598-1

16 Jullien M, Trudel S, Tessoulin B, Mahe B, Dubruille V, Blin N, Gastinne T, Bonnet A, Lok A, Lebourgeois A, Peterlin P, Garnier A, Chevalier P, Guillaume T, Thomare P, Le Gouill S, Moreau $\mathrm{P}$ and Touzeau C: Single-agent daratumumab in very advanced relapsed and refractory multiple myeloma patients: A real-life single-center retrospective study. Ann Hematol 98(6): 14351440, 2019. PMID: 30874850. DOI: 10.1007/s00277-01903655-5 